Sharif University of Technology
Scientia Iranica
Transactions E: Industrial Engineering
hCIENTIA

\title{
A multi-stage stochastic programming model for sustainable closed-loop supply chain network design with financial decisions: A case study of plastic production and recycling supply chain
}

\author{
A.S. Mohammadi ${ }^{a}$, A. Alemtabriz ${ }^{a, *}$, M.S. Pishvaee ${ }^{b}$, and M. Zandieh \\ a. Department of Industrial Management, Faculty of Management and Accounting, University of Shahid Beheshti, Tehran, Iran. \\ b. School of Industrial Engineering, Iran University of Science and Technology, Tehran, Iran.
}

Received 16 July 2017; received in revised form 10 July 2018; accepted 17 November 2018

KEYWORDS
Supply chain
management;
Sustainability;
Stochastic
programming;
Supply chain network
design;
Multi-objective
optimization.

KEYWORDS

Supply chain

programming;

Supply chain network

Multi-objective

optimization.

\begin{abstract}
This paper proposes a multi-objective, multi-stage programming model to design a sustainable closed-loop supply chain network considering financial decisions. A multi-product, sustainable closed-loop plastic Supply Chain Network Design (SCND) problem, which encompasses economic, environmental, and social objectives, is modeled in a mathematical manner. The decisions to be made were concerned with the location of facilities, flow of products, loans to take, and investments to make. Uncertainty issue was about the demand of customers and the rate of return on investment. The decision making model was formulated as a multi-objective, multi-stage mixed-integer linear programming problem and solved by implementing path formulation and augmented $\varepsilon$ constraint methods. Computational analysis was carried out based on the subject company to determine the significance of the proposed model and the efficiency of integrating financial decisions with SCND decisions.
\end{abstract}

(C) 2020 Sharif University of Technology. All rights reserved.

\section{Introduction}

With recent advances, globalization, and unpredictable behaviors of customers and competitors, the field of competition has been converted from firms to supply chains. Consequently, Supply Chain Management (SCM) is one of the most sought topics in logistics. Moreover, Supply Chain Network Design (SCND) is a strategic decision contributing to supply chain. Integrating several strategic and tactical decisions like

*. Corresponding author. Fax: +982122431645

E-mail addresses: amirsalar.mohammadi@gmail.com (A.S. Mohammadi); a-tabriz@sbu.ac.ir (A. Alemtabriz);

pishvaee@iust.ac.ir (M.S.Pishvaee); m_zandieh@sbu.ac.ir (M. Zandieh)

doi: $10.24200 /$ sci. 2019.21531 determining the locations, number and capacity of facilities, and material flow through the network makes SCND a complex issue in the field of SCM.

Previously, minimizing total cost or maximizing profit was the main objective of supply chain and pioneering in the economic dimension was sufficient to outperform the rivals. However, in recent years, supply chains have become responsible for the Environmental Impact (EI) and Social Impact (SI) of their activities. This concern has led to the development of a new concept in SCM, namely Sustainable Supply Chain Management (SSCM), which is defined as considering EI and SI of supply chain activities as well as economic performance in management of material, information, and capital flow $[1,2]$. With respect to the need for sustainability in SCM, some researches have propose models in SCND context. However, the literature on 
sustainable SCND that covers all the three aspects of sustainability (i.e., economic, environmental, and social) is scarce [3]. Recently, Eskandarpour et al. [4] reviewed 87 papers that used mathematical models in the field of SCND and included economic factors together with environmental and/or social dimensions. Based on their analysis, only in $11 \%$ of the reviewed articles all the three dimensions of sustainable development in SCND models were addressed.

To avoid sub-optimality that originates from separate modeling of forward and reverse SCNs, some researchers have focused on developing integrated forward and reverse SCND models [5]. Appropriately established Close-Loop SC (CLSC) can assist firms to decrease the undesired EI of End-Of-Life (EOL) products and to achieve more economic benefits by recapturing the value of used products and increasing their green image in the market. The objective of closed-loop supply chain is closely related to that of SSCM [4]. Accordingly, in the body of the literature on Sustainable Supply Chain Network Design (SSCND), closed-loop SSCND problems have been the major issue among researchers in the recent years [6].

An important challenge associated with SCND problems is to determine the manner of handling the uncertain nature of some future conditions, which may influence input parameters of the problem. Uncertainty can be affiliated to economic, legal, and political issues and it affects parameters like the level of demand, production cost, supply of raw materials, etc. To cope with this issue in the context of SSCND, many authors have proposed a number of stochastic programing models.

Recently, a two-stage stochastic programming approach was applied by Giarola et al. [7] and Verma et al. [8] to manage uncertainties in single-objective environmental supply chain design. Pishvaee et al. [9] introduced Robust Possibilistic Programming (RPP) as a programming approach to coping with uncertain parameters in their bi-objective model, including minimizing the total cost and maximizing $\mathrm{SC}$ Social Responsibility (SR). A computational framework has been proposed to quantify the probable role of uncertainty in the environmental damage for the multi-objective optimization of sustainable supply chain in [10]. A multi-objective (economic and environmental factors) facility location model, which investigates the impact of demand and return uncertainties on the SCND by implementing scenariobased stochastic programming, has been introduced by Amin and Zhang [11]. Ruiz-Femenia et al. [12] presented a stochastic multi-scenario Mixed-Integer Linear Program (MILP) in which demand uncertainty was considered for the multi-objective optimization of chemical supply chain and economic and environmental performances were accounted for, simultaneously. The fact that it is better to consider uncertainty and risk in SSCND researches has been emphasized by Eskandarpour et al. [4].

According to Shapiro [13], strategic-level supply chain studies should attempt to incorporate relevant corporate financial decisions in data-driven models. However, in most of the common approaches to SCND problems, only the physical aspects of $\mathrm{SC}$ are of concern with some perspective on financial decisions in the body of literature [14]. Implementing investment decisions and incorporating loans in financial decisions in SCND problem have been addressed in [15]. An optimal financing strategy for supply chain by considering capital constraint is discussed in [16]. Most researchers usually take into account the financial aspects such as financial factors [14] and financial flows of SC, while few studies address financial decisions in the SCND model as decision variables.

In some cases, it is enough to consider a singleperiod model to develop an ideal solution to the SCND problem. Nevertheless, problems with financial and capital expenditure-related decisions should be planned by implementing multi-period planning models [17]. Furthermore, developing a multi-period setting of this model in addition to the nature of financial decisions may lead to multi-stage stochastic programming. Financial decision making involves a sequence of decisions to react to outcomes that evolve over time periods and multi-stage stochastic programming introduces a proper strategy to cope with the complexity of this issue in the SSCND problem [18]. The method was applied by Nickel et al. [15] to solve an SCND problem with financial decisions and uncertainty assumption for demand and interest rate, where uncertainty was presented by a set of scenarios. Despite the importance of the integrity of financial and physical aspects in SCND problems, to the best of the authors' knowledge, the financial aspect has been completely ignored by researches in the context of sustainable SCND. A list of the above-mentioned and some other studies in the field of sustainable supply chain is provided in Table 1.

To fill the gap in the literature on SSCND, a comprehensive multi-stage stochastic mixed-integer linear programming model for a real-life multi-period multiproduct multi-objective closed-loop SSCND problem with financial decisions and risk consideration subject to investment return rate and demand uncertainty is proposed in this article. This is the first time that financial decisions are applied to the SSCND problem in a research study. Additionally, for the first time, an SSCND model is developed with all the abovementioned features of multiple objectives, multiple products, multiple periods, risk measure, uncertainty issue, financial decisions, and closed loop and all the three dimensions of sustainable development operating in a simultaneous manner are followed. The proposed 
Table 1. Sustainable Supply Clain Network Design futures in the body of literature.

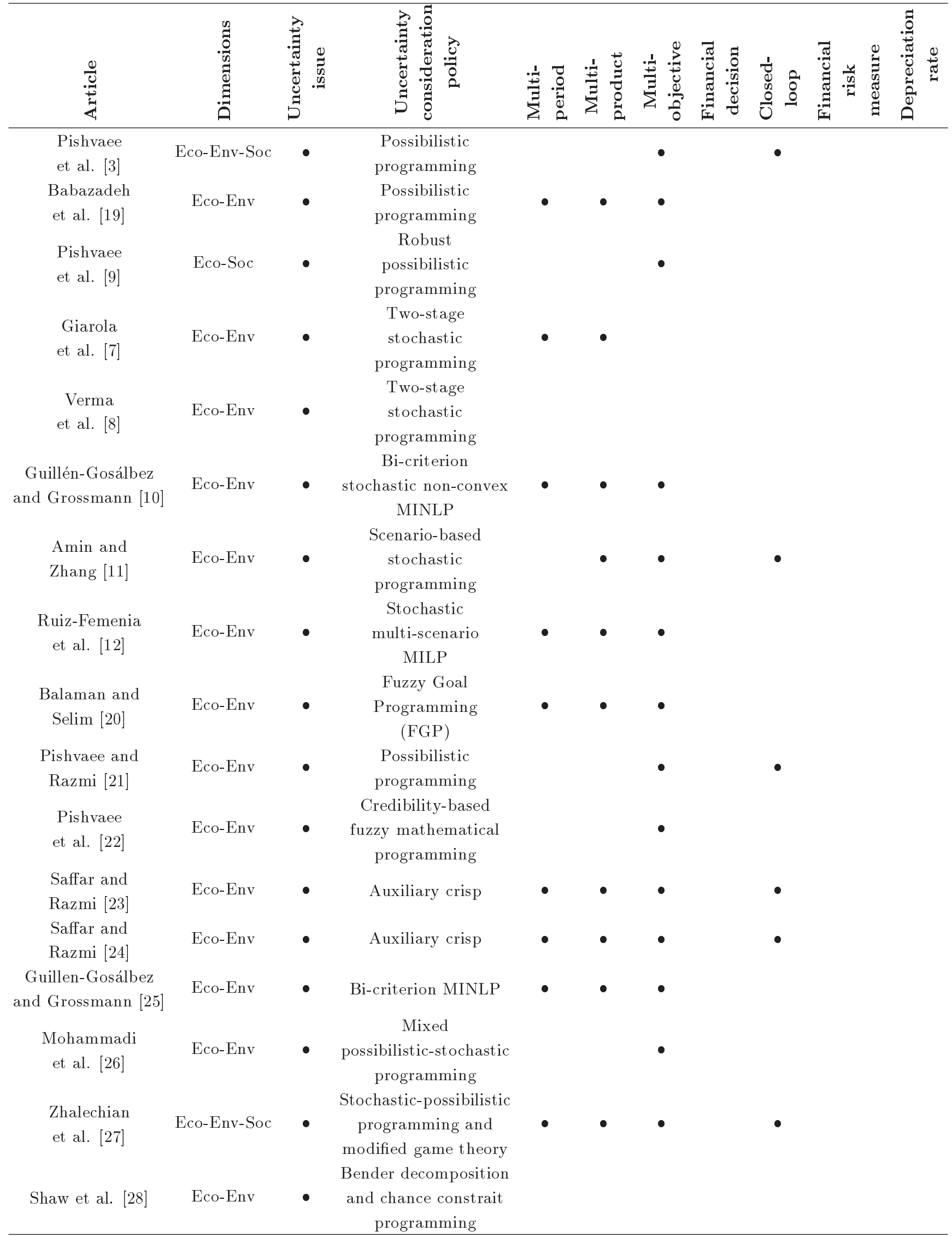


Table 1. Sustainable Supply Clain Network Design futures in the body of literature (continued).

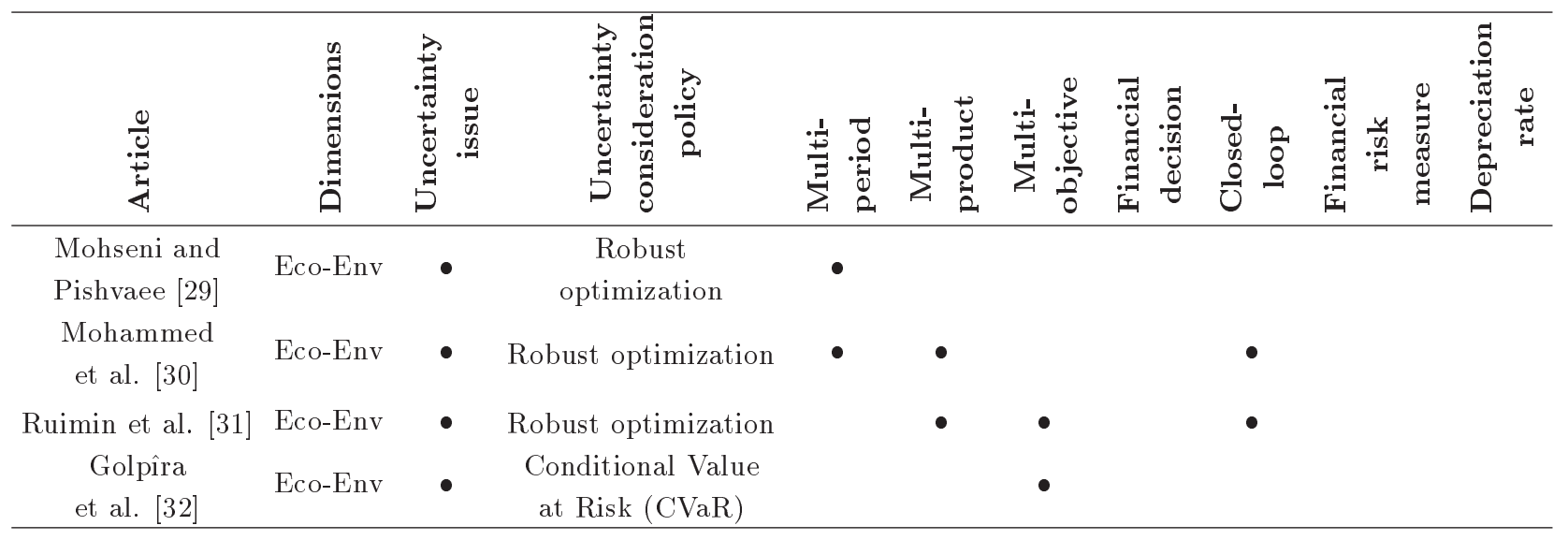

model is adopted in designing a real plastic production and recycling supply chain as a case study through which the practical value of this research will be proved.

The rest of this paper is organized as follows. The real industrial problem is defined and illustrated in Section 2. The problem is formulated as a multiobjective multi-stage stochastic programming model in Section 3. Section 4 is devoted to implementing and presenting the scenario path formulation method. Section 5 deals with the results of the computational analysis of the problem and addresses the value of considering financial decisions. The value of the multistage stochastic problem is measured in Section 6 and the study is concluded in Section 7 .

\section{Problem definition}

In the last 60 years, plastic has become one of the most practical materials with a wide range of applications. In 2014, around 311 million tons of plastic were produced all over the world and 25.8 million tons of post-consumer plastics waste ended up in the waste upstream only in the European Union (EU), while $30.8 \%$ of the plastic wastes are still in the landfills in the EU [33]. Chemically speaking, some reports state that plastic materials take hundreds of years to break down in a landfill. In Iran, 17000 tons of plastics are produced annually. Therefore, it can be deduced that managing EOL of different plastic products is a vital issue, which can affect all the three dimensions of sustainable development.

The logistics network discussed in this article, as illustrated in Figure 1, is formed based on a real Iranian plastic production and recycling supply chain with five echelons of production and recycling center, retailers, customers, collection centers, and landfill centers. A new product is produced by recycling EOL products at different production and recycling centers and then, shipped to retailers based on their demand and availability of the product. Some customers return

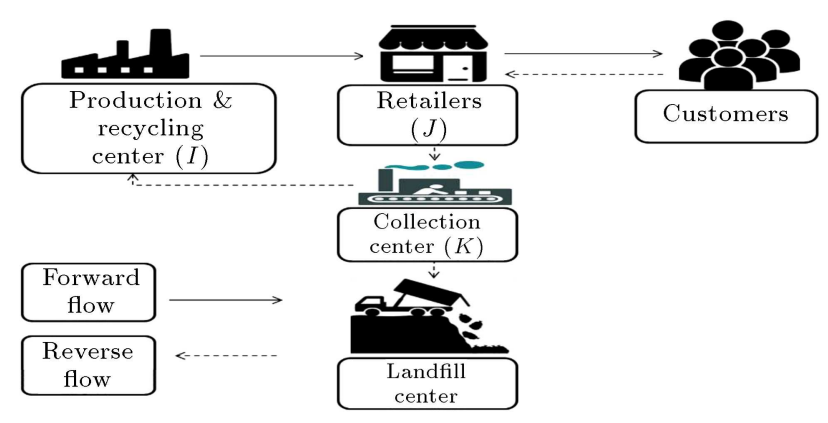

Figure 1. The underlying structure of the concerned supply chain network .

EOL products to retailers and retailers send them to collection centers. The recyclable EOL products are separated and shipped to production and recycling centers and the remaining are sent to the landfill center. Uncertainty is associated with demand and return rate, and multi-period planning horizon is considered. The problem is about finding the optimal decision in each period for: location of facilities, production (or collection) technology, investments to make, loans to take, and flow of products between facilities.

Each period is divided into two consecutive phases of before and after knowing the demand and return rate on investments [15]. Decisions made on location of facilities, production technology, investment, and loans should be made in the first phase and decisions regarding the flow of products between facilities in the second phase.

It is assumed that phase-one decisions can change from one period to another one. Retailers, customers, and the landfill center are already fixed and location decisions are about production and recycling centers, and collection centers. In addition, it is assumed that customers pay their debts at the ends of time periods. This assumption contributes to better conceiving the financial decisions and parameters.

Financial decisions are investment- and loanrelated. Various investment alternatives can be con- 
sidered for a corporate which is making decisions on the SCND problem. Investments in stock market, bonds, real state, supply chain tangible assets, and supply chain intangible assets are considered as the alternatives in the problem. In addition, deciding on how to leverage financial power of a given corporate by taking loan is another strategic financial decision considered in the problem. Diverse loans with different interest rates, payback times, and payback policies are among the loan alternatives. Return On Investment (ROI) was implemented as an index to evaluate financial decisions in [15]. In this study, a target was set for ROI and its downside risk was minimized. This policy is adopted in this study to evaluate and control the financial performance of the subject. Construction and equipment depreciation rate is another financial parameter influencing ROI. This parameter was not considered in [15] and has not been a matter of concern in the SSCND literature. Nevertheless, depreciation rate of facilities is an important parameter that can affect economic performance of supply chain in long term.

Uncertainty is associated with demand and return rates of different investment alternatives. A set of events are considered in assessing the uncertainty of stochastic parameters, where each event consists of demand sub-events and return rate sub-events (defined as an event that declares only one of the stochastic parameters), which are combined in one event and demonstrate both stochastic parameters in a simultaneous manner. For more information about scenario creation, interested readers can refer to [34].

Each time period is divided into two phases in which decisions are made separately. There exist a problem and an Objective Function (OF) in each phase with the objective of achieving reasonable balance among the three dimensions of sustainability. Decisions on investments, locations, and loans should be made in the first phase and decision on shipment should be made in the second phase.

\subsection{Environmental Impact (EI)}

To move towards sustainable design in supply chain networks, it is necessary to implement methods and apply tools to measure EI in different SCND decisions. Each product has different EIs in various stages of its life cycle. Accordingly, appropriate frameworks should be applied to estimating and assessing the EIs related to the whole life cycle of products. Life Cycle Assessment (LCA) is a popular component for quantifying and assessing the EI of a product [35]. In order to quantify and assess the EI of products, an LCA-based damage-oriented method named Eco-indicator 99 [36] is adopted in this study. User friendly units named Eco-indicators, which enable researchers to aggregate and calculate LCA results in an easily understandable manner, are introduced in Eco-indicator 99. This method comprises three damage categories of human health, ecosystem quality, and resources [37].

\subsection{Social Impact (SI) assessment}

$\mathrm{SR}$ is a multi-disciplinary and multi-stakeholder phenomenon and its complex nature and extensive scope make its measurement difficult. However, during the past years, many efforts have been made to support planning and implementing corporate SR. A number of standards such as ISO 26000 [38], SA 8000 [39], and AA 1000 [40] have been developed to provide a comprehensive framework for implementing SR. The International Guidance Standard on SR-ISO 26000 [38] has been introduced by the ISO as an inclusive framework for standard implementation of SR in firms and corporations. ISO 2600 classifies SR issues into seven core subjects:

1. Organizational governance;

2. Human rights;

3. Labor practices;

4. The environment;

5. Fair operating practices;

6. Consumer issues;

7. Community involvement and development.

In this study, SR measures with the following features are selected:

1. Relevant to SCND decisions;

2. Simply quantified;

3. Compatible with the social issues of the region of the case study.

Accordingly, first, stakeholder categories of SC are identified. Next, the SI of supply chain on each stakeholder category is determined based on their social priorities. Finally, some quantitative measures are assigned to each SI. The information about stakeholders, their concerned SI, and relevant quantitative measures is presented in Table 2 .

\subsection{Assumptions, objectives, and constraints}

Based on the above-mentioned problems, the proposed model follows the following assumptions:

- The location decisions can change from one period to another one;

- Retailers, customers, and landfill centers are already fixed;

- Customers pay their debts at the ends of time periods;

- Meeting the whole demand of customers is not necessary; 
Table 2. Stakeholders, their concerned Social Impacts (SIs), and relevant quantitative measures.

\begin{tabular}{lll}
\hline \multicolumn{1}{c}{ Stakeholder } & \multicolumn{1}{c}{ Concerned SI } & \multicolumn{1}{c}{ Relevant quantitative measure(s) } \\
\hline $\begin{array}{l}\text { Workers (production and } \\
\text { collection workers in addition } \\
\text { to transportation workers) }\end{array}$ & Health and safety & $\begin{array}{l}\text { The average number of lost days caused by } \\
\text { damages-average annual road accidents }\end{array}$ \\
Local inhabitants & Delocalization, unemployment & $\begin{array}{l}\text { Number of created job opportunities- } \\
\text { importance rate of region based on } \\
\text { development, unemployment rate }\end{array}$ \\
& Health and safety & $\begin{array}{l}\text { The fraction of potentially harmful products } \\
\text { Consumers }\end{array}$ \\
& $\begin{array}{l}\text { Delocalization, unemployment, } \\
\text { economic development }\end{array}$ & $\begin{array}{l}\text { Number of created job opportunities- } \\
\text { importance rate of region based on } \\
\text { development, unemployment rate }\end{array}$ \\
\hline
\end{tabular}

- There is no flow between facilities of the same echelon.

The main objectives of this model consist of:

- Maximization of total revenue and service level = Revenue of production and recycling centers + Revenue of collection centers + Revenue of other investments - Cost of loans - Risk of falling below the target ROI + Customer service level;

- Minimization of EI = EIs of production + EIs of shipment + EIs of facility establishment;

- Maximization of SR = Introduced job opportunities + Value of local development - Consumer risk Damage to health of workers.

To accomplish the above-mentioned objectives, decision makers face the following constraints:

- Flow balance at network facilities;

- Meeting capacity;

- Meeting customer demand by considering service level;

- Non-negativity and binary constraints on decision variables;

- Considering the budget available at the beginning of each period.

\section{Model formulation}

The indices, parameters, and variables applied to formulating the concerned SSCND problem are described below:

\section{Indices}

$i \quad$ Index of potential location for production center

j Index of retailer $k \quad$ Index of potential location for collection center

$t \quad$ Index of periods in the planning horizon, $t=\{1,2, \cdots, T\}$

$p \quad$ Index of products

$m \quad$ Index of potential investments (indirect in the supply chain and alternative investments)

$b \quad$ Index of potential loans

$q \quad$ Index of technology

\section{Technical parameters}

$K_{i}^{q} \quad$ Capacity of production center $i$ with technology $q$

$K C_{k}^{q} \quad$ Capacity of collection center $k$ with technology $q$

$\mu_{p i}^{q} \quad$ Unit capacity consumption factor of product $p$ by technology $q$ at production center $i$

$\varepsilon_{p k}^{q} \quad$ Unit capacity consumption factor of product $p$ by technology $q$ at collection center $k$

$\beta_{j} \quad$ Weight (importance) of retailer $j$

$D F_{p} \quad$ Maximum downfall rate of collected product $p$ during the recycling process (difference between the weights of the collected waste material and recycled product due to washing of the pollution and impurity of waste material)

$M F_{p} \quad$ Minimum downfall rate of collected product $p$ during the recycling process

\section{Economic (cost and financial) parameters}

$C_{i q}^{t} \quad$ Fixed cost of opening production center $i$ in period $t$ with technology $q$ 
$Q_{k q}^{t} \quad$ Fixed cost of opening collection center $k$ in period $t$ with technology $q$

$V_{i j p}^{t} \quad$ Cost for shipping one unit of product $p$ from production center $p$ to retailer $j$ in period $t$

$V c_{j k p}^{t} \quad$ Cost for shipping one unit of wasted product $p$ from retailer $j$ to collection center $k$ in period $t$

$V r_{k i p}^{t} \quad$ Cost for shipping one unit of wasted product $p$ from collection center $k$ to production center $i$ in period $t$

$R_{i j p}^{t} \quad$ Unitary revenue of product $p$ at production center $i$ shipped to retailer $j$ in period $t$ (i.e., selling price minus purchasing and operation costs)

$Z_{k i p}^{t} \quad$ Unitary revenue of collected product $p$ wastage at collection center $k$ shipped to production center $i$ in period $t$ (i.e., selling price minus purchasing and collection costs)

$\eta_{b}^{t} \quad$ Interest rate of loan $b$ payback at the end of period $t$. This interest rate is always defined for all periods. If no interest rate arises in a period, it is set to zero

ROI Target ROI

$\phi_{m}^{t} \quad$ Rate of return on an investment $m$ paid at the end of period $t$

$B D^{t} \quad$ Exogenous budget available at the beginning of period $t$

$\hbar_{i q} \quad$ Depreciation rate related to production center $i$ with technology $q$ in each period

$\gamma_{k q} \quad$ Depreciation rate related to collection center $k$ with technology $q$ in each period

$\varsigma \quad$ Weight of the downside risk at the $\mathrm{OF}$

\section{Environmental parameters}

$e n_{p}^{q} \quad$ EI of producing one unit of product $p$ with technology $q$

$e m_{i j}^{p} \quad$ EI of shipping one unit of product $p$ from recycling center $i$ to retailer $j$

$e x_{j k}^{p} \quad$ EI of shipping one unit of used product $p$ from retailer $j$ to collection center $k$

$e y_{k i}^{p} \quad$ EI of shipping one unit of collected product $p$ from collection center $k$ to recycling center $i$

$e c_{k p}^{q} \quad$ EI of collecting one unit of wasted product $p$ at collection center $k$ with technology $q$ $e s_{i}^{q} \quad$ EI associated with establishing recycling center $i$ with technology $q$

$e t_{k}^{q} \quad$ EI associated with establishing collection center $k$ with technology $q$

\section{Social parameters}

$u n_{i} \quad$ Unemployment rate at location $i$

$u p_{k} \quad$ Unemployment rate at location $k$

$j \mathrm{o}_{i}^{q} \quad$ Number of introduced job opportunities if a recycling center is opened at location $i$ with technology $q$

$j p_{k}^{q} \quad$ Number of introduced job opportunities if a collection center is opened at location $k$ with technology $q$

$r d_{i} \quad \begin{cases}1 & \begin{array}{l}\text { importance rate of location } i \text { if } \\ \text { its region is developed } \\ 1.3\end{array} \\ \text { important rate of location } i \text { if } \\ \text { its region is undeveloped }\end{cases}$

$r v_{k} \quad \begin{cases}1 & \begin{array}{l}\text { importance rate of location } k \text { if } \\ \text { its region is developed } \\ 1.3\end{array} \\ \text { important rate of location } k \text { if } \\ \text { its region is undeveloped }\end{cases}$

$l w_{i}^{q} \quad$ The average number of lost days in each period due to damages during the producing at production center $i$ with technology $q$

$l m_{k}^{q} \quad$ The average number of lost days in each period due to damages during the collection at collection center $k$ with technology $q$

$r a_{i j} \quad$ The average of annual vehicle accidents occurring on the path from recycling center $i$ to retailer $j$

$r t_{j k} \quad$ The average of annual vehicle accidents occurring on the path from retailer $j$ to collection center $k$

$r c_{k i} \quad$ The average of annual vehicle accidents occurring on the path from collection center $k$ to recycling center $i$

$f l_{p}^{q} \quad$ The fraction of potentially harmful products $p$ which harm the consumer when technology $q$ is applied

ws The weight given to objective SI in terms of health and safety of the worker

$w j \quad$ The weight given to objective SI in terms of employment and delocalization

we The weight given to objective SI in terms of economic development

$w c \quad$ The weight given to objective SI in terms of customer health and safety 


\section{Stochastic parameters (technical and economic)

$\begin{array}{ll}\omega^{t} & \text { Event in period } t \\ \omega^{0} & \text { Current state of nature } \\ \Omega^{t} & \begin{array}{l}\text { Random variable representing the } \\ \text { events that may occur in period } t\end{array} \\ \Omega^{0} & \begin{array}{l}\text { Normal state in the beginning of the } \\ \text { planning horizon }\end{array} \\ p\left(\Omega^{t}=\omega^{t}\right) & \text { Probability of event } \omega^{t} \\ \phi_{m}^{t}\left(\Omega^{t}\right) & \text { Rate of return on an investment } m \\ \phi_{m}^{t}=\phi_{m}^{t}\left(\omega^{t}\right) & \text { paid at the end of period } t \\ D P_{j p}^{t}\left(\Omega^{t}\right) & \text { One realization of } \phi_{m}^{t}\left(\Omega^{t}\right) \\ D P_{j p}^{t}=D P_{j p}^{t}\left(\omega^{t}\right) \text { One realization of } D P_{j p}^{t}\left(\Omega^{t}\right)\end{array}$

\section{Financial decision variables}

$R_{m}^{t} \quad$ Amount of money spent in the available investment $m$ in period $t$

$L_{b}^{t} \quad$ Amount of money obtained from loan $b$ in period $t$

$D R \quad$ Downside Risk

$S L_{j} \quad$ Service level for retailer $j$

\section{Physical decision variables}

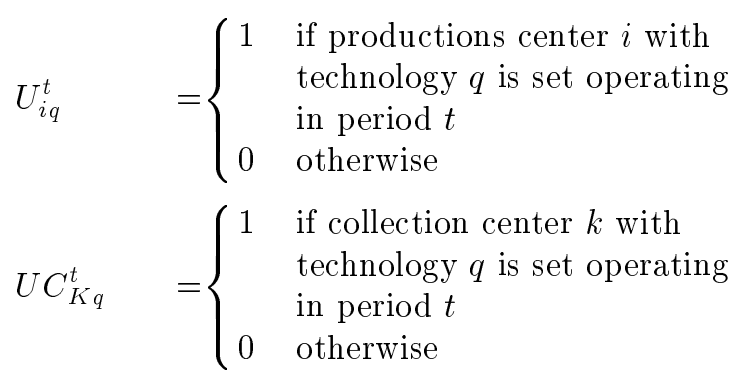

$X_{i j p}^{t} \quad$ Amount of product $p$ shipped from production center $i$ to retailer $j$ in period $t$

$U_{j k p}^{t} \quad$ Amount of returned materials $p$ shipped from retailer $j$ to collection center $k$ in period $t$

$M_{k i p}^{t} \quad$ Amount of collected materials for product $p$ shipped from collecting center $k$ to production center $i$ in period $t$

In order to formulate the multi-stage mixedinteger programming model for the SSCND problem, first, each of the periods is divided into two phases and then, different problems are introduced for different periods (stages). Accordingly, the beginning of each time period is denoted by $t^{-}$and the end by $t^{+}$.

\section{Beginning of period 1}

As mentioned in Section 2, at the beginning of each time period, it is necessary to make decision about facility locations, investments, and loans. Problem objectives consist of:

1. Maximizing expected profit at the end of period one and in period two;

2. Minimizing EI of selected facilities at SCN;

3. Maximizing SI of facility decisions.

$\max$

$$
\begin{aligned}
Q^{-1}= & \sum_{\omega^{1}} P\left(\Omega^{1}=\omega^{1}\right) * Q^{+1}\left(U^{1} \cdot U C^{1} \cdot D P^{1}\right) \\
& +\sum_{\omega^{1}} P\left(\Omega^{1}=\omega^{1}\right) * Q^{-1}\left(\phi^{1} \cdot R^{1} \cdot L^{1}\right)
\end{aligned}
$$

$\min \quad N^{-1}=\sum_{i} \sum_{q} u_{i q}^{1} e s_{i}^{q}+\sum_{i} \sum_{q} u c_{k q}^{1} e t_{k}^{q}$

$$
\begin{aligned}
& +w e\left(\sum_{i} \sum_{q} u_{i q}^{1} r d_{i}+\sum_{k} \sum_{q} u c_{k q}^{1} r v_{k}\right) \\
& -w s\left(\sum_{i} \sum_{q} u_{i q}^{1} l w_{i}^{q}+\sum_{k} \sum_{q} u c_{k q}^{1} l m_{k}^{q}\right),
\end{aligned}
$$

s.t.:

$$
\begin{array}{ll}
B D^{1}-\sum_{i} \sum_{q} C_{i q}^{1} U_{i q}^{1}-\sum_{k} \sum_{q} Q_{k q}^{1} U C_{k q}^{1}-\sum_{m} R_{M}^{1} \\
\quad+\sum_{b} L_{b}^{1} \geq 0 & \\
U_{i q}^{1} \cdot U C_{k q}^{1} \in\{0 ; 1\} \quad \forall i . k . q \\
r d_{i} \cdot r v_{k} \in\{1 ; 1.3\} \quad \forall i . k, \\
u n_{i} \cdot u p_{k} \in[0 ; 1] \quad \forall i . k, \\
R_{M}^{1} \cdot L_{b}^{1} \geq 0 \quad \forall M . b .
\end{array}
$$

The expected profit and SI of decisions are respectively maximized by OFs (1) and the third part of OF given in Eq. (2); the total EI is minimized by the first part of OF given in Eq. (2). Budget availability for the first stage of the problem is assessed by Constraint (3). Available budget in addition to the loans cannot be lower than investments and opening cost of facilities. Binary and non-negativity restrictions on decision variables, which should be made at the beginning of the first period, are enforced by Constraints (4), (5), and (6), respectively, and importance rate of locations is presented by Constraint (7). 


\section{End of period 1}

After making decisions about facility locations, investments, and loans in the beginning of the first period, and determining the demand at the end of the period, decisions on shipment of materials among facilities should be made.

$$
\begin{aligned}
\max Q^{+1}= & \sum_{i} \sum_{j} \sum_{p} \sum_{k}\left(\left(R_{i j p}^{1}-V_{i j p}^{1}\right) X_{i j p}^{1}\right. \\
& \left.+\left(Z_{k i p}^{1}-V r_{k i p}^{1}-\left(U_{j k p}^{1} . V c_{j k p}^{1}\right)\right) M_{k i p}^{1}\right) \\
& *(1+R O I)^{T-1}, \\
\min N^{+1}= & \sum_{i} \sum_{j} \sum_{q}\left(e n_{p}^{q}+e m_{i j}^{p}\right) X_{i j p}^{1} \\
& +\sum_{j} \sum_{k} \sum_{p} e x_{j k}^{p} U_{j k p}^{1} \\
& +\sum_{i} \sum_{k} \sum_{p}\left(e y_{k i}^{p}+e c_{k p}^{q}\right) * M_{k i p}^{1}
\end{aligned}
$$

s.t.:

$$
\begin{array}{ll}
\sum_{p} \mu_{p i}^{q} * \sum_{j} X_{i j p}^{1} \leq K_{i}^{q} * U_{i q}^{1} & \forall q . i, \\
\sum_{p} \varepsilon_{p k}^{q} * \sum_{i} M_{k i p}^{1} \leq K C_{k}^{q} * U C_{k q}^{1} & \forall q \cdot k, \\
\sum_{i} X_{i j p}^{1} \leq D P_{j p}^{1} \quad \forall j \cdot p, &
\end{array}
$$$$
\sum_{k} M_{k i p}^{1}\left(1-M F_{p}\right) \leq \sum_{j} X_{i j p}^{1} \leq \sum_{k} M_{k i p}^{1}\left(1-D F_{p}\right)
$$$$
\forall i . p,
$$

$$
\begin{array}{lr}
X_{i j p}^{1} \cdot M_{k i p}^{1} \geq 0 & \forall i . j \cdot p \cdot k, \\
M F_{p} \cdot D F_{p} \in[0 ; 1] & \forall p .
\end{array}
$$

OF (8) maximizes revenue of collection centers and recycling centers in the first period as well as multiple revenues of SCN in the target $\mathrm{ROI}$ in order to consider ROI of the earned revenue in future periods. The EI is minimized by the first part of given in Eq. (9) and SI of shipment decisions is maximized by the third part of OF given in Eq. (9). Constraints (10) and (11) are related to capacity constraints of recycling centers and collection centers. Surplus supply to retailers is prevented through Constraint (12). The amount of the flow of materials among collection and recycling centers is balanced through Inequality (13) by considering downfall rate of collected materials at recycling centers. Collected plastics downfall weight is the result of wiping impurities during the washing process at recycling centers with an important effect on SC planning of plastic recycling industry. The nonnegativity restriction on shipment decision variables is enforced by Constraint (14) and the permitted value for downfall rates is indicated by Constraint (15).

\section{Beginning of period $t \in\{2, \cdots, T-1\}$}

At the beginning of $t \in\{2, \cdots, T-1\}$, decisions regarding locations, investments, and loans should be reconsidered. Consequently, the following subproblem must be solved at the beginning of period $t \in\{2, \cdots, T-1\}$.

$$
\begin{aligned}
\max Q^{-t}= & \sum_{\omega^{t}} P\left(\Omega^{t}=\omega^{t}\right) * Q^{+t}\left(U^{t} \cdot U C^{t} \cdot D P^{t}\right) \\
& +\sum_{\omega^{t}} P\left(\Omega^{t}=\omega^{t}\right) * Q^{-(t+1)}\left(\phi^{t} \cdot R^{t} \cdot L^{t}\right), \\
\min N^{-t}= & \sum_{i} \sum_{q} u_{i q}^{t} e s_{i}^{q}+\sum_{i} \sum_{q} u c_{k q}^{t} e t_{k}^{q}, \\
\max S^{-t}=w j & \left(\sum_{i} \sum_{q} u_{i q}^{t} j o_{i}^{q} u n_{i}\right. \\
& \left.+\sum_{k} \sum_{q} u c_{k q}^{t} j p_{k}^{q} u p_{k}\right) \\
& +w e\left(\sum_{i} \sum_{q} u_{i q}^{t} r d_{i}+\sum_{k} \sum_{q} u c_{k q}^{t} r v_{k}\right) \\
& -w s\left(\sum_{i} \sum_{q} u_{i q}^{t} l w_{i}^{q}+\sum_{k} \sum_{q} u c_{k q}^{t} l m_{k}^{q}\right)
\end{aligned}
$$

s.t.:

$$
\begin{aligned}
& B D^{t}-\sum_{i} \sum_{q} C_{i q}^{t} U_{i q}^{t}-\sum_{k} \sum_{q} Q_{k q}^{t} U C_{k q}^{t}-\sum_{m} R_{M}^{t} \\
& +\sum_{b} L_{b}^{t}+\sum_{t=1}^{t-1}\left(\sum_{m} \phi_{m}^{t} \cdot R_{m}^{t}-\sum_{b} \eta_{b}^{t} . L_{b}^{t}\right) \geq 0, \\
& U_{i q}^{t} \cdot U C_{k q}^{t} \in\{0 ; 1\} \quad \forall i . k . q, \\
& L_{b}^{t} . R_{m}^{t} \geq 0 \quad \forall \text { b.m.t. }
\end{aligned}
$$

The expected profit and SI of decisions are maximized by OFs (16) and (18). OF (17) is applied to minimizing the total EI. In Constraint (19), revenue of the previous periods is added to the available budget and the amount of the loans that should be paid back in period $t$ is subtracted from the available budget. Non-negative and binary nature of decision variables at the beginning of period $t$ are presented by Constraints (20) and (21), respectively. 
End of period $t \in\{2, \cdots, T-1\}$

$$
\begin{aligned}
\max Q^{+t}= & \sum_{i} \sum_{j} \sum_{p} \sum_{k}\left(\left(R_{i j p}^{t}-V_{i j p}^{t}\right) X_{i j p}^{t}\right. \\
& \left.+\left(Z_{k i p}^{t}-V r_{k i p}^{t}-\left(U_{j k p}^{t} . V c_{j k p}^{t}\right)\right) M_{k i p}^{t}\right) \\
& *(1+R O I)^{T-t}
\end{aligned}
$$

$\min \quad N^{+t}=\sum_{i} \sum_{j} \sum_{q}\left(e n_{p}^{q}+e m_{i j}^{p}\right) X_{i j p}^{t}$

$$
\begin{aligned}
& +\sum_{j} \sum_{k} \sum_{p} e x_{j k}^{p} U_{j k p}^{t} \\
& +\sum_{i} \sum_{k} \sum_{p}\left(e y_{k i}^{p}+e c_{k p}^{q}\right) * M_{k i p}^{t},
\end{aligned}
$$

$$
\max \quad S^{+t}=-w s\left(\sum_{i} \sum_{j} \sum_{p} X_{i j p}^{t} r a_{i j}\right.
$$$$
+\sum_{j} \sum_{k} \sum_{p} U_{k q}^{t} r t_{j k}
$$$$
\left.+\sum_{i} \sum_{k} \sum_{p} M_{k i p}^{t} r c_{k i}\right)
$$$$
-w c\left(\sum_{i} \sum_{j} \sum_{p} X_{i j p}^{t} f l_{p}^{q}\right) \text {, }
$$

s.t.:

$$
\begin{array}{ll}
\sum_{p} \mu_{p i}^{q} * \sum_{j} X_{i j p}^{t} \leq K_{i p}^{q} * U_{i q}^{t} & \forall q . i, \\
\sum_{p} \varepsilon_{p k}^{q} * \sum_{i} M_{k i p}^{t} \leq K C_{k p}^{q} * U C_{k q}^{t} & \forall q . k \\
\sum_{i} X_{i j p}^{t} \leq D P_{j p}^{t} & \forall j . p \\
\sum_{k} M_{k i p}^{t}\left(1-M F_{p}\right) \leq \sum_{j} X_{i j p}^{t} \leq \sum_{k} M_{k i p}^{t}\left(1-D F_{p}\right)
\end{array}
$$$$
\forall \text { i.p, }
$$

$$
X_{i j p}^{t} \cdot M_{k i p}^{t} \geq 0 \quad \forall i . j . p . k .
$$

OF (22) is used to maximize revenue of collection centers and recycling centers in period $t$ as well as multiple revenues of SCN in the target ROI in order to consider ROI of the earned revenue in future periods. EI is minimized by OF (23) and OF (24) is applied to maximizing SI of shipment decisions. Constraints (25) and (26) are related to capacity constraints of recycling centers and collection centers, respectively.
Surplus supply to retailers is prevented by Constraint (27). The amount of flow of materials between collection centers and recycling centers is balanced by Inequality (28) considering downfall rate of collected materials at recycling centers. The non-negativity restrictions on shipment decision variables are enforced by Constraint (29).

\section{Beginning of period $T$}

The beginning of this period is formulated similarly to that of the previous periods:

$$
\begin{aligned}
\max \quad Q^{-T}= & \sum_{\omega^{T}} P\left(\Omega^{T}=\omega^{T}\right) * Q^{+T}\left(U^{T} \cdot U C^{T} \cdot D P^{T}\right), \\
\min \quad N^{-T}= & \sum_{i} \sum_{q} u_{i q}^{T} e s_{i}^{q}+\sum_{i} \sum_{q} u c_{k q}^{T} e t_{k}^{q}, \\
\max \quad S^{-T}= & w j\left(\sum_{i} \sum_{q} u_{i q}^{T} j o_{i}^{q} u n_{i}\right. \\
& \left.+\sum_{k} \sum_{q} u c_{k q}^{T} j p_{k}^{q} u p_{k}\right) \\
& +w e\left(\sum_{i} \sum_{q} u_{i q}^{T} r d_{i}+\sum_{k} \sum_{q} u c_{k q}^{T} r v_{k}\right) \\
& -w s\left(\sum_{i} \sum_{q} u_{i q}^{T} l w_{i}^{q}+\sum_{k} \sum_{q} u c_{k q}^{T} l m_{k}^{q}\right)
\end{aligned}
$$

s.t.:

$$
\begin{aligned}
& B D^{T}-\sum_{i} \sum_{q} C_{i q}^{T} U_{i q}^{T}-\sum_{k} \sum_{q} Q_{k q}^{T} U C_{k q}^{T}-\sum_{m} R_{m}^{T} \\
& +\sum_{b} L_{b}^{T}+\sum_{t=1}^{T-1}\left(\sum_{m} \phi_{m}^{T-1} * R_{m}^{t}-\sum_{b} \eta_{b}^{T-1} * L_{b}^{t}\right) \geq 0 \\
& U_{i q}^{T} \cdot U C_{k q}^{T} \in\{0 ; 1\} \quad \forall i . k . q, \\
& L_{b}^{T} \cdot R_{m}^{T} \geq 0 \quad \forall \text { b.m.t. }
\end{aligned}
$$

Here, the structure of sub-problems is still the same. The expected profit and SI of the decisions that should be made at the beginning of period $T$ are maximized by OFs (30) and (32), respectively, and the total EI of these decisions is minimized through OF (31). In Constraint (33) the revenue of the previous periods is added to the available budget and the amount of loans that should be paid back in period $t$ is subtracted from the available budget. Non-negative and binary nature of decision variables at the beginning of period $T$ are presented by Constraints (34) and (35), respectively. 


$$
\begin{gathered}
\sum_{t}\left(\left(\sum_{m} \phi_{m}^{T} \cdot R_{m}^{T}-\sum_{b} \eta_{b}^{T} \cdot L_{b}^{T}\right)+\sum_{i} \sum_{j} \sum_{p} \sum_{p}\left(\left(R_{i j p}^{t}-V_{i j p}^{t}\right) * X_{i j p}^{t}+\left(Z_{k i p}^{t}-V r_{k i p}^{t}\right.\right.\right. \\
D R \geq 1-\frac{\left.\left.\left.-\left(U_{j k p}^{t} \cdot V c_{j k p}^{t}\right)\right) \cdot M_{k i p}^{t}\right)\right) *(1+R O I)^{T-t}-\sum_{i} \sum_{q}\left(\hbar_{i q}\right) * U_{i q}^{T} * C_{i q}^{T}-\sum_{k} \sum_{q}\left(\gamma_{k q}\right) \cdot U C_{k q}^{T} \cdot Q_{k q}^{T}}{\sum_{t} B G^{t} \cdot(1+R O I)^{T-t+1}} .
\end{gathered}
$$

Box I

\section{End of period T}

The following problem is formulated for the end of the planning horizon:

$$
\begin{aligned}
\max Q^{+T}= & \sum_{i} \sum_{j} \sum_{p} \sum_{k}\left(\left(R_{i j p}^{T}-V_{i j p}^{T}\right) X_{i j p}^{T}\right. \\
& \left.+\left(Z_{k i p}^{T}-V r_{k i p}^{T}-\left(U_{j k p}^{T} * V c_{j k p}^{T}\right)\right) M_{k i p}^{T}\right) \\
& +\sum_{j} \beta_{j} * S L_{j}-\varsigma D R \\
& +\sum_{t=1}^{T}\left(\sum_{m} \phi_{m}^{T} * R_{m}^{T}-\sum_{b} \eta_{b}^{T} * L_{b}^{T}\right) \\
& -\sum_{i} \sum_{q}\left(\hbar_{i q}\right) * U_{i q}^{T} * C_{i q}^{T} \\
& -\sum_{k} \sum_{q}\left(\gamma_{k}^{q}\right) * U C_{k q}^{T} * Q_{k q}^{T},
\end{aligned}
$$

$\min \quad N^{+T}=\sum_{i} \sum_{j} \sum_{q}\left(e n_{p}^{q}+e m_{i j}^{p}\right) X_{i j p}^{T}$

$$
\begin{aligned}
& +\sum_{j} \sum_{k} \sum_{p} e x_{j k}^{p} U_{j k p}^{T} \\
& +\sum_{i} \sum_{k} \sum_{p}\left(e y_{k i}^{p}+e c_{k p}^{q}\right) * M_{k i p}^{T},
\end{aligned}
$$

$\max S^{+T}=-w s\left(\sum_{i} \sum_{j} \sum_{p} X_{i j p}^{T} r a_{i j}\right.$

$$
\begin{aligned}
& +\sum_{j} \sum_{k} \sum_{p} U_{k q}^{T} r t_{j k} \\
& \left.+\sum_{i} \sum_{k} \sum_{p} M_{k i p}^{T} r c_{k i}\right) \\
& -w c\left(\sum_{i} \sum_{j} \sum_{p} X_{i j p}^{T} f l_{p}^{q}\right),
\end{aligned}
$$

s.t.:

$$
\begin{aligned}
& \sum_{p} \mu_{p i}^{q} * \sum_{j} X_{i j p}^{T} \leq K_{i p}^{q} * U_{i q}^{T} \quad \forall q . i, \\
& \sum_{p} \varepsilon_{p k}^{q} * \sum_{i} M_{k i p}^{T} \leq K C_{k p}^{q} * U C_{k q}^{T} \quad \forall q . k, \\
& \sum_{i} X_{i j p}^{T} \leq D P_{j p}^{T} \quad \forall j \cdot p, \\
& \sum_{k} M_{k i p}^{T}\left(1-M F_{p}\right) \leq \sum_{j} X_{i j p}^{T} \leq \sum_{k} M_{k i p}^{T}\left(1-D F_{p}\right) \\
& \forall i . p
\end{aligned}
$$

Eq. (43) is shown in Box I.

$$
\begin{aligned}
& \forall j, \\
& S L_{j} \in[0 ; 1] \quad \forall j, \\
& D R \geq 0 .
\end{aligned}
$$$$
\sum_{i} \sum_{t} \sum_{p} X_{i j p}^{t} \geq S L_{j} * \sum_{t} \sum_{p} D P_{j p}^{t}
$$

In OF (36), the following extra terms are considered in comparison with the end of the previous periods. For this purpose, first, the depreciation rates of the production and collection centers are subtracted from total revenue; second, the service level is maximized; third, the downside risk is minimized; and forth, the total loans payback and total investment revenue are considered. The EI and SI of OFs are similar to those in the previous periods. Inequalities (39)-(42) represent the production centers capacity, collection centers capacity, demand, and downfall constraints, respectively. The downside risk of the target ROI, which is minimized in OF (36), is calculated through Inequality (43). Finally, the service level for each customer, which is maximized in OF (36), is determined by Constraint (44). 


\section{Solution approach}

The above-mentioned formulation of SSCND with financial decisions problem explicitly pertains to the concept and multi-stage structure of the problem. Analysis of the interactions among variables proves that the decisions made on locations, investments, loans, and shipments are connected to each other and affect service level and downside risk at the end of the time horizon.

The problem was simplified in the model in the previous section. However, for solving and implementing the problem, a more compact model compatible with the general solver is needed. The path formulation method for solving a multi-stage SCND problem was introduced by Nickel et al. [15], in which the sequence of events was defined as a scenario; then, the path and sub-paths for each scenario were determined. The following new notation is introduced before presenting the path formulation model:

\section{Scenario path formula}

- $S^{t}=\Omega^{1} \times \Omega^{2} \times \cdots \times \Omega^{t}$ : The set for the potential sequence of events up to period $t$;

- $s^{t} \in S^{t}=\left(\omega^{0} \times \omega^{1} \times \cdots \times \omega^{t}\right)$ : Path of events from the root node to one particular node in period $t$;

- $s^{0}:$ Root node;

- $s^{T}$ : Path of the events oriented from the root node to a leaf node (a scenario);

- $\operatorname{path}_{s^{t}}=\left\{s^{0} \cdot s^{1} \cdots s^{t}\right\}$ : Set of all sub-paths containing parts of path $s^{t}$;

- $P\left(S^{t}=s^{t}\right)=\prod_{t=1}^{t} p\left(\Omega^{t}=\omega^{t}\right)$ : The probability that the sequence of the events passes through path $s^{t}$.

The problem is reformulated as follows:

$$
\begin{aligned}
\max Q= & \sum_{t} \sum_{s^{t} \in S^{t}} P\left(S^{t}=s^{t}\right) \\
& *\left[\sum _ { i } \sum _ { j } \sum _ { p } \sum _ { k } \left(\left(R_{i j p}^{t}\right.\right.\right. \\
& \left.\left.-V_{i j p}^{t}\right) X_{i j p}^{t}\left(s^{t}\right)\right)+\left(Z_{k i p}^{t}-V r_{k i p}^{t}\right. \\
& \left.\left.\left.-\left(U_{j k p}^{t}\left(s^{t}\right) * V c_{j k p}^{t}\right)\right) * M_{k i p}^{t}\left(s^{t}\right)\right)\right] \\
& +\sum_{s^{T} \in S^{T}} P\left(S^{T}=s^{T}\right) *\left[\sum_{j} \beta_{j}\right. \\
& * S L_{j}\left(s^{T}\right)-\varsigma * D R\left(s^{T}\right)
\end{aligned}
$$

$$
\begin{aligned}
& +\sum_{t} \sum_{s^{t-1} \in \operatorname{path}_{s} T}\left(\sum_{m} \phi_{m}^{t}\left(s^{T}\right)\right. \\
& \left.* R_{m}^{t}\left(s^{t-1}\right)-\sum_{b} \eta_{b}^{t}\left(s^{T}\right) * L_{b}^{t}\left(s^{t-1}\right)\right) \\
& -\sum_{i} \sum_{q}\left(\hbar_{i q}\right) * U_{i q}^{T}\left(s^{t-1}\right) * C_{i q}^{T} \\
& \left.-\sum_{k} \sum_{q}\left(\gamma_{k q}\right) * U C_{k q}^{T}\left(s^{t-1}\right) * Q_{k q}^{T}\right] .
\end{aligned}
$$

$\min$

$$
\begin{aligned}
N= & \sum_{t} \sum_{s^{t} \in S^{t}} P\left(S^{t}=s^{t}\right) \\
& *\left[\sum_{q} \sum_{p} \sum_{i} \sum_{j}\left(e n_{p}^{q}-e m_{i j}^{p}\right) X_{i j p}^{t}\left(s^{t}\right)\right. \\
& +\sum_{j} \sum_{k} \sum_{p} e n_{j k}^{p} * U_{j k p}^{t}\left(s^{t}\right) \\
& \left.+\sum_{q} \sum_{p} \sum_{k} \sum_{i}\left(e y_{k i}^{p}+e c_{k p}^{q}\right) * M_{k i p}^{t}\left(s^{t}\right)\right] \\
& +\sum_{t} \sum_{s^{t} \in S^{t}} P\left(S^{t}=s^{t}\right) \\
& *\left[\sum_{i} \sum_{q} U_{i q}^{T} * e s_{i}^{q}\right. \\
& \left.+\sum_{k} \sum_{q} U C_{k q}^{T} * e t_{k}^{q}\right],
\end{aligned}
$$

$\max \quad S=\sum_{t} \sum_{s^{t} \in S^{t}} P\left(S^{t}=s^{t}\right)$

$$
\begin{aligned}
& *\left[-w s\left(\sum_{i} \sum_{j} \sum_{p} X_{i j p}^{t}\left(s^{t}\right) * r a_{i j}\right.\right. \\
& +\sum_{j} \sum_{k} \sum_{p} U_{j k p}^{t}\left(s^{t}\right) * r t_{j k} \\
& \left.+\sum_{k} \sum_{i} \sum_{p} M_{k i p}^{t}\left(s^{t}\right) * r c_{k i}\right) \\
& \left.-w c\left(\sum_{i} \sum_{j} \sum_{p} \sum_{q} X_{i j p}^{t}\left(s^{t}\right) * f l_{p}^{q}\right)\right] \\
& +\sum_{t} \sum_{s^{t} \in S^{t}} P\left(S^{t}=s^{t}\right)
\end{aligned}
$$




$$
\begin{aligned}
& *\left[w j \left(\sum_{i} \sum_{q} U_{i q}^{t}\left(s^{t-1}\right) * j o_{i}^{q} * u n_{i}\right.\right. \\
& \left.+\sum_{k} \sum_{q} U C_{k q}^{t}\left(s^{t-1}\right) * j p_{k}^{q} * u p_{k}\right) \\
& +w e\left(\sum_{i} \sum_{q} U_{i q}^{t}\left(s^{t-1}\right) * r d_{i}\right. \\
& \left.+\sum_{k} \sum_{q} U C_{k q}^{t}\left(s^{t-1}\right) * r v_{k}\right) \\
& -w s\left(\sum_{i} \sum_{q} U_{i q}^{t}\left(s^{t-1}\right) * l w_{i}^{q}\right. \\
& \left.\left.+\sum_{k} \sum_{q} U C_{k q}^{t}\left(s^{t-1}\right) * l m_{k}^{q}\right)\right]
\end{aligned}
$$

s.t.:

$$
\begin{aligned}
B D^{1} & -\sum_{i} \sum_{q} C_{i q}^{1} U_{i q}^{1}\left(s^{0}\right)-\sum_{k} \sum_{q} Q_{k q}^{1} U C_{k q}^{1}\left(s^{0}\right) \\
& -\sum_{m} R_{M}^{1}\left(s^{0}\right)+\sum_{b} L_{b}^{1}\left(s^{0}\right) \geq 0
\end{aligned}
$$$$
B D^{t}-\sum_{i} \sum_{q} C_{i q}^{t} U_{i q}^{t}\left(s^{t-1}\right)-\sum_{k} \sum_{q} Q_{k q}^{t} U C_{k q}^{t}\left(s^{t-1}\right)
$$$$
-\sum_{m} R_{M}^{t}\left(s^{t-1}\right)+\sum_{b} L_{b}^{t}\left(s^{t-1}\right)
$$$$
+\sum_{t=1}^{t-1}\left(\sum_{m} \phi_{m}^{t} * R_{m}^{t}\left(s^{t-1}\right)-\sum_{b} \eta_{b}^{t} * L_{b}^{t}\left(s^{t-1}\right)\right)
$$$$
\geq 0
$$

$$
\sum_{p} \mu_{p i}^{q} * \sum_{i} X_{i j p}^{t}\left(s^{t}\right) \leq K_{i}^{q} * U_{i q}^{t}\left(s^{t-1}\right) \quad \forall q \cdot j,
$$$$
\sum_{p} \varepsilon_{p k}^{q} * \sum_{i} M_{k i p}^{t}\left(s^{t}\right) \leq K C_{k}^{q} * U C_{k q}^{t}\left(s^{t-1}\right)
$$$$
\forall q \cdot k
$$

$$
\begin{aligned}
& \sum_{i} X_{i j p}^{t}\left(s^{t}\right) \leq D P_{j p}^{t}\left(s^{t}\right) \quad \forall j . p \\
& \sum_{k} M_{k i p}^{t}\left(1-M F_{p}\right) \leq \sum_{j} X_{i j p}^{t} \leq \sum_{k} M_{k i p}^{t}\left(1-D F_{p}\right) \\
& \quad \forall i . p,
\end{aligned}
$$

Eq. (56) is shown in Box II.

$$
\begin{aligned}
& \sum_{i} \sum_{t} \sum_{p} X_{i j p}^{t}\left(s^{t}\right) \geq S L_{j} * \sum_{t} \sum_{p} D P_{j p}^{t}\left(s^{t}\right) \\
& \forall j \cdot s^{t}, \\
& U_{i q}^{1} \cdot U C_{k q}^{1} \in\{0 ; 1\}, \\
& X_{i j p}^{t}\left(s^{t}\right) \cdot M_{k i p}^{t}\left(s^{t}\right) \cdot D P_{j p}^{t}\left(s^{t}\right) \cdot R_{m}^{t}\left(s^{t-1}\right) \cdot L_{b}^{t}\left(s^{t-1}\right) \\
& . D R\left(s^{T}\right) \geq 0 \quad \forall i \cdot j \cdot p \cdot k \cdot m \cdot b, \\
& S L_{j}\left(s^{T}\right) \in[0 ; 1] \quad \forall j .
\end{aligned}
$$

The concept of the above path formulation model is completely based on the multi-period, multi-product CL_SSCND problem explained in Section 3, in which every combination of events is considered as a scenario. Here, every scenario consists of different sequences of events (paths). Probability of each path in a scenario is calculated by multiplying probability of the events in a path. Finally, the OFs are computed based on the probabilities of scenarios (Eqs. (44)-(46)). An example of the scenario trees with 3 periods and 2 possible events in each period is depicted in Figure 2. The specified lines in red color demonstrate a scenario which encompasses event 2 in period 1 , event 1 in period 2, and event 1 in period 3 .

The SSCND problem is multi-objective in nature. To solve the multi-objective programming models, there exist many methods. In this article, $\varepsilon$-constraint method is adopted to deal with the multi-objective nature of the SSCND problem. Several versions of the $\varepsilon$-constraint method have been proposed in the body of literature. Here, the augmented $\varepsilon$-constraint (AUGMECON) method proposed by Mavrotas [41] is adopted. In comparison with other versions of the $\varepsilon$ constraint method, AUGMECON is able to:

$$
\begin{array}{r}
\sum_{s^{T}} \sum_{t}\left(\left(\sum_{m} \phi_{m}^{T}\left(s^{T}\right) * R_{m}^{T}\left(s^{t-1}\right)-\sum_{b} \eta_{b}^{T}\left(s^{T}\right) * L_{b}^{T}\left(s^{t-1}\right)\right)+\sum_{i} \sum_{j} \sum_{p} \sum_{p}\left(\left(R_{i j p}^{t}-V_{i j p}^{t}\right) * X_{i j p}^{t}\left(s^{t}\right)+\left(z_{k i p}^{t}-V r_{k i p}^{t}\right.\right.\right. \\
D R \geq 1-\frac{\left.\left.\left.-\left(U_{j k p}^{t} \cdot V c_{j k p}^{t}\right)\right) * M_{k i p}^{t}\left(s^{t}\right)\right)\right) \cdot(1+R O I)^{T-t}-\sum_{i} \sum_{q}\left(\hbar_{i q}\right) * U_{i q}^{T}\left(s^{t-1}\right) * C_{i q}^{T}-\sum_{k} \sum_{q}\left(\gamma_{k q}\right) * U C_{k q}^{T}\left(s^{t-1}\right) * Q_{k q}^{T}}{\sum_{t} B G^{t} *(1+R O I)^{T-t+1}} .
\end{array}
$$




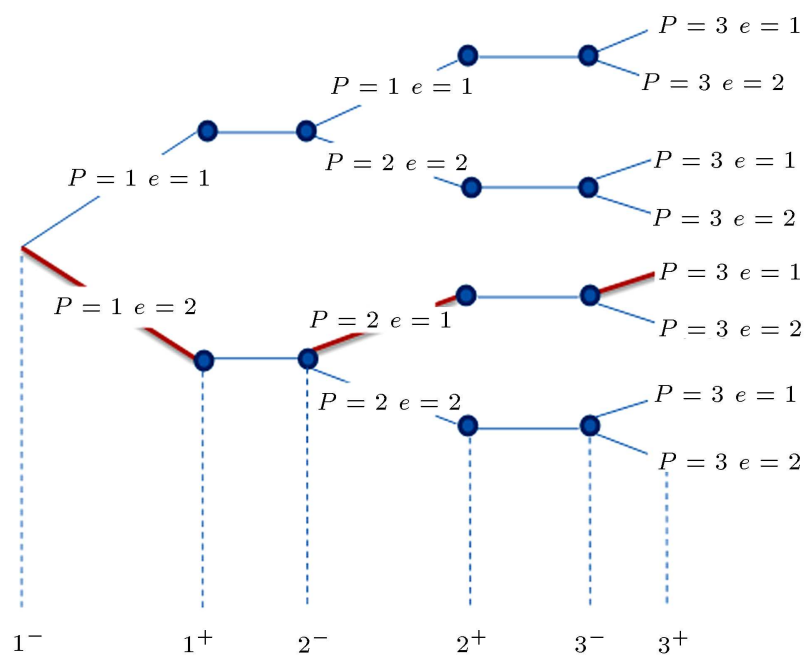

Figure 2. An example of the scenario trees.

1. Guarantee efficiency of the obtained solution;

2. Calculate the range of the OFs over the efficient set;

3. Offer acceptable solution time in the cases with several objectives [41].

In order to solve the problem by the abovementioned method, first, the economic objective presented in OF (47) is considered as the main objective and OFs (48) and (49) are expressed in the form of inequality constraints. Then, environmental $\mathrm{OF}$ is optimized by adding economic $\mathrm{OF}=Q^{*}$ as an equality constraint and OF (49) as an inequality constraint. Subsequently, the social OF is optimized by considering economic $\mathrm{OF}=Q^{*}$ and environmental $\mathrm{OF}=N^{*}$ as constraints. Consequently, payoff matrix of the problem is employed as a tool for calculating the ranges of OFs. In the next step, economic OF is taken as the one to be optimized and the ranges of environmental and social OFs are separated into the same intervals. Based on the defined intervals, constraints related to environmental and social OFs are taken into account for defining some sub-problems. Therefore, the Pareto set is obtained by solving each sub-problem. In order to avoid inefficiency of the $\varepsilon$-constraint method, slack variable technique is deployed based on augmented $\varepsilon$ constraint method [41]. Finally, the decision maker selects the most desired solution among all the derived non-dominated solutions.

\section{Implementation and evaluation}

The validity of developed model and the functionality of the solution method are assessed through the data for the considered case study. The subject firm here has 20 customers and 10 candidate locations are considered for production and collection centers. This firm can produce two products with two different technologies

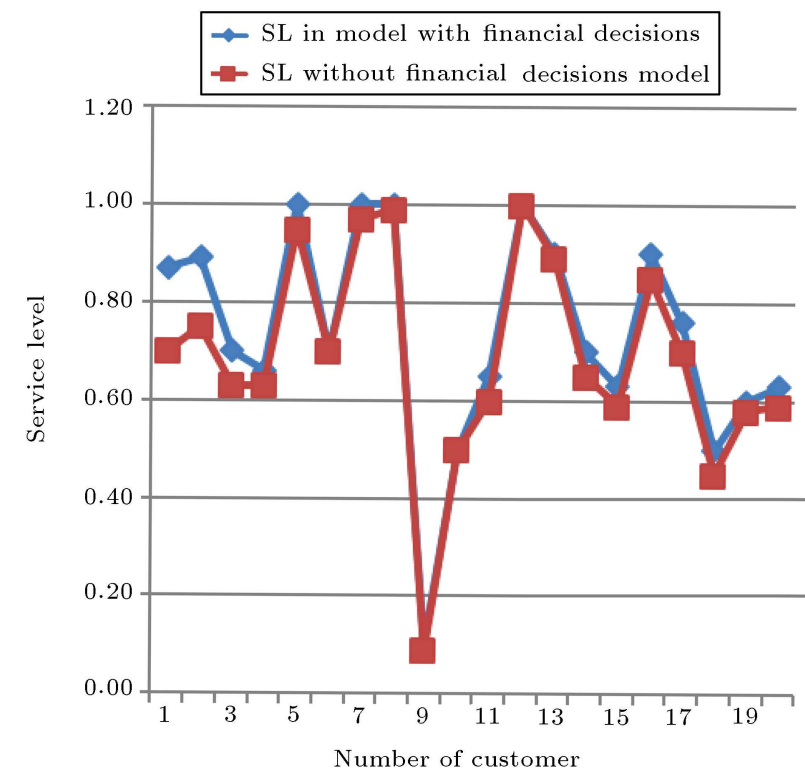

Figure 3. Comparison between service levels in the models with and without financial decisions.

and each technology has a different depreciation rate. The firm has 6 investment alternatives with different rates of return and different variances. Besides the available exogenous budget, the manager of the firm has the opportunity to give 5 different loans with different payback times and payback types.

The proposed model is coded and solved through IBM ILOG CPLEX 12.1. A time limit of 3600 seconds is considered in this process. The results are tabulated in Table 3.

In order to evaluate effectiveness of considering financial decisions in the SSCND problem, the proposed model is solved without considering financial decisions. The results for the problem solved without taking financial decisions are tabulated in Table 4.

Tables 3 and 4 confirm that by solving the model with financial decisions, both the customer service level and $\mathrm{OF}$ value increase, indicating that financial leveraging with loans and considering other investment alternatives besides investment in SCN can improve the physical and financial performance of SCN. Considering financial decision in the studied firm increases service level by $6 / 531 \%$ and OF value by $12 / 56 \%$. The comparison between the amounts of service level in the financial and non-financial models is given in Figure 3.

The above-mentioned results have been achieved by considering five loan alternatives, which can be added to the available budget of investors. A sensitivity analysis has been run on the number of available loans. Decreasing the number of available loans reduces the financial leveraging power of investors. The fact that more financial leverage increases the economic value of this model is illustrated in Figure 4.

By taking advantage of the available loans, in- 
Table 3. Result for the problem solved by financial decisions.

\begin{tabular}{|c|c|c|c|c|}
\hline $\begin{array}{l}\text { Number and } \\
\text { region of } \\
\text { customers }\end{array}$ & $\begin{array}{c}\text { Service level of } \\
\text { customer during the } \\
\text { whole time horizon }\end{array}$ & $\begin{array}{c}\text { Weighted average of } \\
\text { the service level } \\
\text { of the whole system }\end{array}$ & $\begin{array}{c}\text { Value of the economic } \\
\mathrm{OF}^{\mathrm{a}} \text { at the end of } \\
\text { the final period }\end{array}$ & $\begin{array}{c}\text { Downside risk } \\
\text { related to the } \\
\text { value of the } \mathrm{OF}\end{array}$ \\
\hline $1=$ Isfahan & 0.87 & \multirow{20}{*}{0.7487} & \multirow{20}{*}{465868} & \multirow{20}{*}{0.15} \\
\hline $2=$ Isfahan & 0.89 & & & \\
\hline $3=$ Isfahan & 0.70 & & & \\
\hline $4=$ Isfahan & 0.66 & & & \\
\hline $5=$ Isfahan & 1.00 & & & \\
\hline $6=$ Isfahan & 0.70 & & & \\
\hline $7=$ Isfahan & 1.00 & & & \\
\hline $8=$ Tehran & 1.00 & & & \\
\hline $9=$ Hormozgan & 0.10 & & & \\
\hline $10=$ Azerbaijan & 0.50 & & & \\
\hline $11=$ Isfahan & 0.65 & & & \\
\hline $12=$ Tehran & 1.00 & & & \\
\hline $13=$ Isfahan & 0.90 & & & \\
\hline $14=$ Isfahan & 0.70 & & & \\
\hline $15=$ Markazi & 0.63 & & & \\
\hline $16=$ Khoozestan & 0.90 & & & \\
\hline $17=$ Isfahan & 0.76 & & & \\
\hline $18=$ Fars & 0.50 & & & \\
\hline $19=$ Khorasan & 0.60 & & & \\
\hline $20=$ Yazd & 0.63 & & & \\
\hline
\end{tabular}

${ }^{\mathrm{a} O F}$ : Objective Function.

Table 4. Result for the problem solved without financial decisions.

\begin{tabular}{|c|c|c|c|c|}
\hline $\begin{array}{c}\text { Number and } \\
\text { region of } \\
\text { customers }\end{array}$ & $\begin{array}{c}\text { Service level of } \\
\text { customer during the } \\
\text { whole time horizon }\end{array}$ & $\begin{array}{c}\text { Weighted average of } \\
\text { the service level of } \\
\text { the whole system }\end{array}$ & $\begin{array}{c}\text { Value of the economic } \\
\mathrm{OF}^{\mathrm{a}} \text { at the end of } \\
\text { the final period }\end{array}$ & $\begin{array}{c}\text { Downside risk } \\
\text { related to the } \\
\text { value of the OF }\end{array}$ \\
\hline $1=$ Isfahan & 0.70 & \multirow{20}{*}{0.7028} & \multirow{20}{*}{413879} & \multirow{20}{*}{0.12} \\
\hline $2=$ Isfahan & 0.75 & & & \\
\hline $3=$ Isfahan & 0.63 & & & \\
\hline $4=$ Isfahan & 0.63 & & & \\
\hline $5=$ Isfahan & 0.95 & & & \\
\hline $6=$ Isfahan & 0.70 & & & \\
\hline $7=$ Isfahan & 0.97 & & & \\
\hline $8=$ Tehran & 0.99 & & & \\
\hline $9=$ Hormozgan & 0.09 & & & \\
\hline $10=$ Azerbaijan & 0.50 & & & \\
\hline $11=$ Isfahan & 0.60 & & & \\
\hline $12=$ Tehran & 1.00 & & & \\
\hline $13=$ Isfahan & 0.89 & & & \\
\hline $14=$ Isfahan & 0.65 & & & \\
\hline $15=$ Markazi & 0.59 & & & \\
\hline $16=$ Khoozestan & 0.85 & & & \\
\hline $17=$ Isfahan & 0.70 & & & \\
\hline $18=$ Fars & 0.45 & & & \\
\hline $19=$ Khorasan & 0.58 & & & \\
\hline $20=$ Yazd & 0.59 & & & \\
\hline
\end{tabular}

${ }^{a} \mathrm{OF}$ : Objective Function. 
Table 5. Sensitivity analysis of the number of available loans.

\begin{tabular}{ccc}
\hline $\begin{array}{c}\text { Number of } \\
\text { available loans }\end{array}$ & $\begin{array}{c}\text { Weighted average of the service } \\
\text { level of the whole system }\end{array}$ & $\begin{array}{c}\text { Value of the economic OF } \\
\text { at at } \\
\text { the end of the final period }\end{array}$ \\
\hline 0 & 0.7197 & 442575 \\
1 & 0.7285 & 449315 \\
2 & 0.7359 & 454773 \\
3 & 0.7419 & 459367 \\
4 & 0.7464 & 463539 \\
5 & 0.7487 & 465868 \\
\hline
\end{tabular}

${ }^{\mathrm{a} O F}$ : Objective Function.

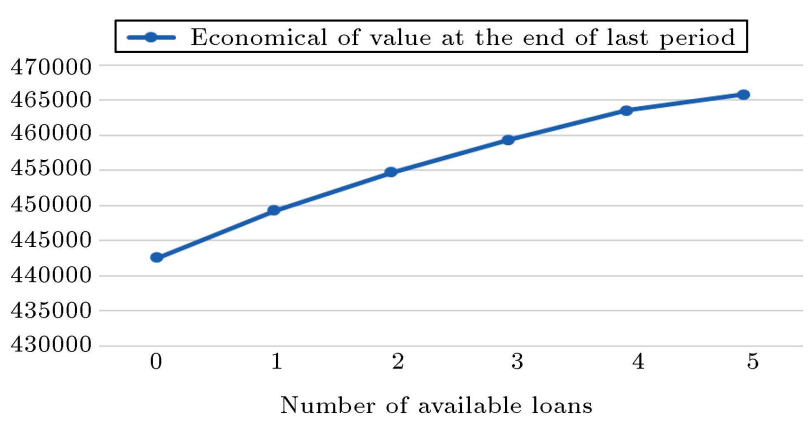

Figure 4. Effect of available loans on economic Objective Function (OF).

vestors can increase the number of facilities, hence raising the amounts of production and sale. In the proposed model, the advantage of taking loans is improving the economic value as far as the profit generated by the sale rises and is sufficient to pay back the loans and their interest. The fact that considering all the available five loans improves the economic OF by $5.26 \%$ and service level of the whole system by $4 \%$ is tabulated in Table 5 .

In general, the above-mentioned tables and figures approve effectiveness of considering financial decisions in SSCND problem. Considering other investment alternatives in addition to SSCN investments provides investors with an overall view to expand their choices. Moreover, the possibility of financial leveraging by getting loans empowers the firms with respect to their financial status. As a result, investors become able to increase profitability of their decisions regarding the SSCND problem.

\section{The relevance of applying a stochastic approach}

When uncertainty is considered in an optimization model, the important issue is to assess its superiority over deterministic methods. Relative Value of Multistage Stochastic Approach (RVMSA) is a measure that calculates this relevance. RVMSA examines the importance of achieving perfect information on stochastic parameters [42] through measuring the dis- tance between stochastic and deterministic values of the problem and dividing the yield distance into the deterministic value of the problem. The result of this division examines the effectiveness of applying multistage stochastic approach.

In order to compute RVMSA, the value of the deterministic problem should be calculated, which is obtained through substituting all random variables with their expected values [15]. To accomplishing this, $\phi_{m}^{t}\left(s^{T}\right)$ is substituted with $E\left[\phi_{m}^{t}\left(s^{T}\right)\right]$ and $D P_{j p}^{t}\left(s^{T}\right)$ is substituted with $E\left[D P_{j p}^{t}\left(s^{T}\right)\right]$.

To analyze the performance of this multi-stage stochastic approach in the context of the introduced problem, the deterministic problem value $\left(Q^{D E T}\right)$ is computed for the subject firm. Here, the RVMSA is measured as follows:

$$
\begin{aligned}
\operatorname{RVMSA} & =\frac{Q^{S T O}-Q^{D E T}}{Q^{D E T}}=\frac{465868-441163}{441163} \\
& =0.056 .
\end{aligned}
$$

The result of RVMSA measurement indicates that solving the problem through this multi-stage stochastic approach can improve supply chain performance in the problem time horizon by $5.6 \%$ in terms of the $\mathrm{OF}$ value. This confirms effectiveness of implementing the multistage stochastic approach in the SSCND problem with financial decisions.

\section{Conclusions}

In this study, integration of physical and financial decisions in Sustainable Supply Chain Network Design (SSCND) problem with uncertainty issue was facilitated by implementing a multi-stage stochastic approach. The main objectives of the proposed multiobjective model consisted of:

1. Maximizing total revenue, maximizing service level to customers, and minimizing deviation from target Return On Investment (ROI);

2. Minimizing Environmental Impact (EI); 


\section{Maximizing social benefits.}

In addition to general decisions made on location and allocation, financial decisions were of concern. Uncertainty was considered in demand and investment rate of return and in order to cope with the uncertainty, a mixed-integer multi-stage stochastic programming formulation was implemented. The applicability of the model was tested by the case study of a real plastic recycling company located in Iran. $\varepsilon$-constraint and path-formulation methods were adopted for handling multi-objectiveness and stochastic nature of the problem. Computational results indicated that considering the financial decisions improved service level and OF value. Moreover, sensitivity analysis proved the benefits of considering loan alternatives in such problems. Loan consideration assists managers to leverage their financial power. Furthermore, Relative Value of Multi-stage Stochastic Approach (RVMSA) index was used to assess the value of implementing multistage stochastic approach and the results indicated that stochastic approach outperformed the deterministic approach.

The results of this paper can be applied to other industries with closed-loop SC structure, such as petrochemical, electrical, etc. The proposed model can be extended in future studies by making improvement in its different aspects. For example, future research can be aimed at implementing other policies for coping with uncertainty and analyzing performance of different policies. Also, it is necessary to evaluate the value of the stochastic approach for social and environmental OFs.

\section{References}

1. Devika, K., Jafarian, A., and Nourbakhsh, V. "Designing a sustainable closed-loop supply chain network based on triple bottom line approach: A comparison of metaheuristics hybridization techniques", Eur. J. Oper. Res., 235(3), pp. 594-615 (2014).

2. Seuring, S. and Müller, M. "From a literature review to a conceptual framework for sustainable supply chain management", J. Clean. Prod., 16(15), pp. 1699-1710 (2008).

3. Pishvaee, M.S., Razmi, J., and Torabi, S.A. "An accelerated Benders decomposition algorithm for sustainable supply chain network design under uncertainty: A case study of medical needle and syringe supply chain", Transp. Res. Part E Logist. Transp. Rev., 67, pp. 1438 (2014).

4. Eskandarpour, M., Dejax, P., Miemczyk, J., and Peton, O. "Sustainable supply chain network design: An optimization-oriented review", Omega (United Kingdom), 54, pp. 11-32 (2015).

5. Soleimani, H., Seyyed-Esfahani, M., and Kannan, G. "Incorporating risk measures in closed-loop supply chain network design", Int. J. Prod. Res., 52(6), pp. 1843-1867 (2014).

6. Srivastava, S.K. "Green supply-chain management: a state-of-the-art literature review", Int. J. Manag. Rev., 9(1), pp. 53-80 (2007).

7. Giarola, S., Shah, N., and Bezzo, F. "A comprehensive approach to the design of ethanol supply chains including carbon trading effects", Bioresour. Technol., 107, pp. 175-185 (2012).

8. Verma, M., Gendreau, M., and Laporte, G. "Optimal location and capability of oil-spill response facilities for the south coast of Newfoundland", Omega, 41(5), pp. 856-867 (2013).

9. Pishvaee, M.S., Razmi, J., and Torabi, S.A. "Robust possibilistic programming for socially responsible supply chain network design: A new approach", Fuzzy sets Syst., 206, pp. 1-20 (2012).

10. Guillén-Gosálbez, G. and Grossmann, I. "A global optimization strategy for the environmentally conscious design of chemical supply chains under uncertainty in the damage assessment model", Comput. Chem. Eng., 34(1), pp. 42-58 (2010).

11. Amin, S.H. and Zhang, G. "A multi-objective facility location model for closed-loop supply chain network under uncertain demand and return", Appl. Math. Model., 37(6), pp. 4165-4176 (2013).

12. Ruiz-Femenia, R., Guillen-Gosalbez, G., Jimenez, L., and Caballero, J.A. "Multi-objective optimization of environmentally conscious chemical supply chains under demand uncertainty", Chem. Eng. Sci., 95, pp. 1-11 (2013).

13. Shapiro, J.F. "Challenges of strategic supply chain planning and modeling", Comput. J.F. (2004). Challenges Strateg. Supply Chain Plan. Model. Comput. Chem. Eng., 28(6), pp. 855-861 (2004).

14. Ramezani, M., Kimiagari, A.M., and Karimi, B. "Closed-loop supply chain network design: A financial approach", Appl. Math. Model., 38(15-16), pp. 40994119 (2014).

15. Nickel, S., Saldanha-da-Gama, F., and Ziegler, H-P. "A multi-stage stochastic supply network design problem with financial decisions and risk management", Omega, 40(5), pp. 511-524 (2012).

16. Wang, B., Huang, D-C., Li, H., and Ding, J-Y. "Optimal decisions and financing strategies selection of supply chain with capital constraint", Math. Probl. Eng., Article ID: 6597259, 14 pages (2016).

17. Melo, M.T., Nickel, S., and Saldanha da Gama, F. "Dynamic multi-commodity capacitated facility location: A mathematical modeling framework for strategic supply chain planning", Comput. Oper. Res., 33(1), pp. 181-208 (2006). 
18. Birge, J. and Louveaux, F. "Introduction to stochastic programming", Springer Ser. Oper. Res. (1997).

19. Babazadeh, R., Razmi, J., Pishvaee, M.S., and Rabbani, M. "A sustainable second-generation biodiesel supply chain network design problem under risk", Omega (United Kingdom), 66, pp. 258-277 (2017).

20. Balaman, S.Y. and Selim, H. "Sustainable design of renewable energy supply chains integrated with district heating systems: A fuzzy optimization approach", $J$. Clean. Prod., 133, pp. 863-885 (2016).

21. Pishvaee, M.S. and Razmi, J. "Environmental supply chain network design using multi-objective fuzzy mathematical programming", Appl. Math. Model., 36(8), pp. 3433-3446 (2012).

22. Pishvaee, M.S., Torabi, S.A., and Razmi, J. "Credibility-based fuzzy mathematical programming model for green logistics design under uncertainty", Comput. Ind. Eng., 62(2), pp. 624-632 (2012).

23. Saffar, M.M. and Razmi, J. "A new bi-objective mixed integer linear programming for designing a supply chain considering CO2 emission", Uncertain Supply Chain Manag., 2(4), pp. 275-292 (2014).

24. Saffar, M.M. and Razmi, J. "A new multi objective optimization model for designing a green supply chain network under uncertainty", Int. J. Ind. Eng. Comput., 6, pp. 15-32 (2015).

25. Guillén-Gosálbez, G. and Grossmann, I.E. "Optimal design and planning of sustainable chemical supply chains under uncertainty", AIChE J., 55(1), pp. 99121 (2009).

26. Mohammadi, M., Torabi, S.A., and TavakkoliMoghaddam, R. "Sustainable hub location under mixed uncertainty", Transp. Res. Part E: Logist. Transp. Rev., 62, pp. 89-115 (2014).

27. Zhalechian, M., Tavakkoli-Moghaddam, R., Zahiri, B., and Mohammadi, M. "Sustainable design of a closedloop location-routing-inventory supply chain network under mixed uncertainty", Transp. Res. Part E Logist. Transp. Rev., 89, pp. 182-214 (2016).

28. Shaw, K., Irfan, M., Shankar, R., and Yadav, S.S. "Computers \& industrial engineering low carbon chance constrained supply chain network design problem: a Benders decomposition based approach", Comput. Ind. Eng., 98, pp. 483-497 (2016).

29. Mohseni, S. and Pishvaee, M.S. "A robust programming approach towards design and optimization of microalgae-based biofuel supply chain", Comput. Ind. Eng., 100, pp. 58-71 (2016).

30. Mohammed, F., Selim, S.Z., Hassan, A., and Syed, M.N. "Multi-period planning of closed-loop supply chain with carbon policies under uncertainty", Transp. Res. Part D Transp. Environ., 51, pp. 146-172 (2017).
31. Ruimin, M.A., Lifei, Y.A.O., Maozhu, J.I.N., Peiyu, R.E.N., and Zhihan, L.V. "Robust environmental closed-loop supply chain design under uncertainty", Chaos, Solitons and Fractals, 89, pp. 195-202 (2016).

32. Golpîra, H., Zandieh, M., Najafi, E., and SadiNezhad, S. "A multi-objective, multi-echelon green supply chain network design problem with risk-averse retailers in an uncertain environment", Sci. Iran. E, 24(1), pp. 413-423 (2017).

33. Plastics Europe, Plastics-The Facts 2013: An Analysis of European Latest Plastics Production, Demand and Waste Data, pp. 1-40 (Oct. 2013).

34. Heitsch, H. and Römisch, W. "Scenario tree modelling for multistage stochastic programs", Math. Program., 118(2), pp. 371-406 (2009).

35. Rebitzer, G., Ekvall, T., Frischknecht, R., Hunkeler, D., Norris, G., Rydberg, T., Schmidt, W., Suh, S., Weidema, B., and Pennington, D.W. "Life cycle assessment: Framework, goal and scope definition, inventory analysis, and applications", Environ. Int., 30(5), pp. 701-720 (2004).

36. Consultants, P., Eco-Indicator 99 Manual for Designers, Minist. Housing, Spat. Plan. Environ. (2000).

37. Goedkoop, M. and Spriensma, R., The Eco-Indicator 99 - A Damage Oriented Method for Life Cycle Impact Assessment, Assessment, p. 144 (2001).

38. International Organization for Standardization, Final Draft International Standard ISO/FDIS 26000, Guidance on Social Responsibility (2010).

39. CEPAA, G., Guidance Document for Social Accountability 8000, Council on Economiuc Priorities Accreditation Agency, New York (1999).

40. Institute of Social and Ethical AccountAbility, AccountAbility 1000 (AA1000) Framework: Standard, Guidelines and Professional Qualification, Institute of Social and Ethical Accountability (1999).

41. Mavrotas, G. "Effective implementation of the constraint method in multi-objective mathematical programming problems", Appl. Math. Comput., 213(2), pp. 455-465 (2009).

42. Nickel, S., Reuter-Oppermann, M., and Saldanha da Gama, F. "Ambulance location under stochastic demand: A sampling approach", Oper. Res. Heal. Care, 8, pp. 24-32 (2016).

\section{Biographies}

Amir Salar Mohammadi accomplished his BSc in Industrial Engineering at Azad University of Najaf Abad, Isfahan, Iran, in 2009 and MSc in Industrial Management at Shahid Beheshti University, Tehran, Iran in 2011. Now, he is working as a PhD candidate at Shahid Beheshti University, Tehran, Iran. His research interests are supply chain management, optimization under uncertainty, and financial engineering. 
Akbar Alemtabriz is a Professor in the Management and Accounting Faculty at Shahid Beheshti University, Tehran, Iran. He received his $\mathrm{PhD}$ in Management from Gazi University, Ankara, Turkey, in 1989. Most of his recent studies have focused on decision making, multi-objective optimization under uncertainty, and supply chain management.

Mir Saman Pishvaee received his $\mathrm{PhD}$ in Industrial Engineering from University of Tehran and now, he is Assistant Professor at Iran University of Science and Technology (IUST). He has published many papers in various journals such as Omega, Transportation Research: Part E (TR-E), Computers \& Operations Research (COR), and Computers \& Industrial Engineering (CAIE) as well as several book chapters under Springer-Verlag in the area of supply chain manage- ment. His research areas are supply chain management, robust optimization, and system dynamics.

Mostafa Zandieh accomplished his BSc in Industrial Engineering at Amirkabir University of Technology, Tehran, Iran, in 1998 and MSc in the same field at Sharif University of Technology, Tehran, Iran, in 2000. He also obtained his $\mathrm{PhD}$ in Industrial Engineering from Amirkabir University of Technology, Tehran, Iran, in 2006. Currently, he is an Associate Professor in the Industrial Management Department of Shahid Beheshti University, Tehran, Iran. His research interests are production planning and scheduling, financial engineering, quality engineering, applied operations research, simulation, and artificial intelligence techniques in the areas of manufacturing systems design. 